\title{
Research and Development a Web Application Management for University Students in Colombia
}

\author{
W. Ruiz, Y. Díaz, and R. Ferro
}

\begin{abstract}
The popularization of the Internet and the use of ICT has brought great and innumerable advantages to multiple users that are interconnected at the time, the arrival of new wireless technologies with improved bandwidth and data transfer protocols has led to a new concept called mobile and ubiquitous networks. We are in a purely mobile world, the arrival of smartphones and tablets with power and efficient operating systems and features that not stop surprising have been adapted by many users as communication devices, entertainment, learning and a number of ends that have changed. The way, we interact in the world and manage to create a concept of mobility in the new holistic dimension of the Web. That is why the CUN and his research Axon group cannot be oblivious to these becoming and technological progress, which is why this project of applied research focuses on making an application for consultation of tutoring students different educational programs of the center seat of the CUN using a Web application that can enhance the timing of academic work by the student teacher and create better professionals and citizens in our country in all the preparatory cycle.
\end{abstract}

Index Terms-Academic tutoring software, technological innovation, UML, Web 3.0.

\section{INTRODUCTION}

In the last decade, the company has increased the use of smart phones and tablets with touch screens and data connection via WiFi [1], 3G and 4G. Currently the mass of these mobile devices has allowed purchase at very low costs allowing that more users can get their hands on an Internet connection [2] from wherever you are and thus can access Web applications real time and can connect to databases and software applications that allow you to have many facilities to perform their work, study or access to educational applications or information to citizens. Similarly, the promotion of training models like Electronic Learning [3]. Mobile-Learning and Blended Learning, and adapt them in the learning process is more evident today in the Education Institutions Superior [4]. The educational processes benefit from the implementation of technological tools and communication. Given that expands learning opportunities to the participants of the academic process.

Information Technology and Communication ICT [5] are just the medium that enables learning among participants in the educational process, factors such as utilization and good use of technology tools given a real need inspired the

Manuscript received August 8, 2015; revised December 1, 2015. This work was supported in part by Axon research group at the CUN University.

The authors are with Informatics Engineering Department, the CUN University, Colombia (e-mail: william_ruizmar@cun.edu.co, yesid_diaz@cun.edu.co,robertoferro@hotmail.com). participants, training educational technology faculty, researchers and students, the quality of the educational content, the development of joint activities and interactions between teachers and students in the academic process that emphasize educational processes through meaningful learning. Allowing the increase of knowledge and the benefit of society is only a click away from any application that is in the Web 2.0 [6]. But when we refer to the Web 2.0 and 3.0 we are confirming the new client paradigm server interactive type that allows the development of new educational forms [7] which they appear in the new century and will permeate the way we attend to work, study and new learning where students are all on the Web [8].

\section{Methodology}

This research is framed within the type of descriptive, qualitative and quantitative research, as it allows us to know the reality of the object of such research through surveys and in our case students of different programs offered by the CUN in based center, thus it is possible to apply the criteria established by Wrightt [9], in order to obtain the "Why", the "How" and "What" of the research project and thus framing the outcome of an investigation applied to solve a particular issue and to obtain a mobile educational application easy to use by its Stakeholders; see a description of process in Fig. 1.

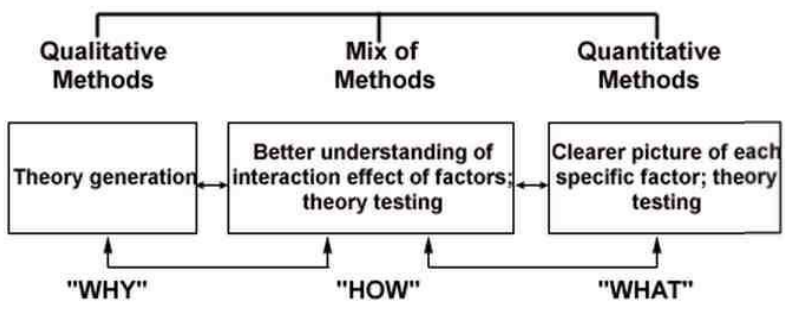

Fig. 1. Research methodology applied to the project CUN [9].

The name this project "Development of a mobile academic ICT application for student assistance," were taken as variables base related to the preparatory cycle, the time at which attended the curricular project, the social stratum they belong to, the age range and most importantly the need for a Web application for academic tutoring without need for physical space or make trips to other sites of the University [10].

The information structure is supported of three basic components. However, despite its simplicity, they are completely dynamic, in the sense that it allows multiple combinations of these elements and enable face the most varied practical situations. The three pieces of information [11] are: 
- The unit of analysis.

- The variable or variables.

- The value.

To achieve proper results it was decided to take the opinion of students from different preparatory cycles, including the gender to which they belong is distinguished, once the population identified shows the cycle of questions start in order and determine the degree of knowledge part of each of the respondents, there is achieved identify the "How" by understanding each of the factors involved in the surveys; once clearly identified the needs encountered is passed to the implementation phase of the tool which presents the development of it and give the test line on the Web site chosen for use by the academic community of the CUN.

\section{DEVELOPMENT OF RESEARCH SURVEYS}

Then each of the questions posed in the survey is apply to each of the 200 students of the sample to determine whether it is feasible or not research and further development of the application

Question 1. Select the academic program to which it belongs, is shown in Fig. 2:

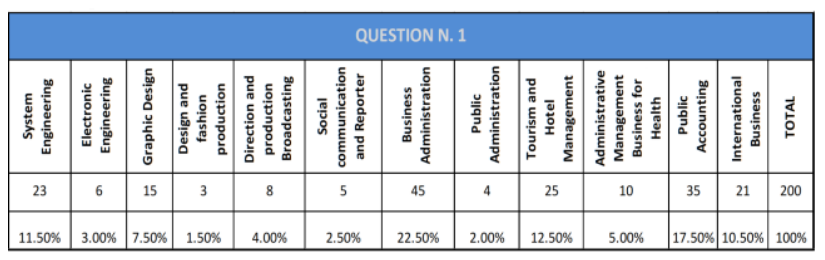

Fig. 2. Sample distribution by academic programs.

Question 2. Indicate the preparatory cycle currently enrolled, is shown in Fig. 3:

\begin{tabular}{|c|c|c|c|}
\hline \multicolumn{5}{|c|}{ Question N. 2 } \\
\hline 1. Technical & 2. Technologist & 3. Professional & TOTAL \\
\hline 116 & 37 & 47 & 200 \\
\hline $58.00 \%$ & $18.50 \%$ & $23.50 \%$ & $100 \%$ \\
\hline
\end{tabular}

Fig. 3. Propedeutic cycle students

Question 3. Survey student day at the program, is shown in Fig. 4:

\begin{tabular}{|c|c|c|}
\hline \multicolumn{3}{|c|}{ Question N. 3 } \\
\hline 1. Day class & 2. Evening class & TOTAL \\
\hline 71 & 129 & 200 \\
\hline $35.50 \%$ & $64.50 \%$ & $100 \%$ \\
\hline
\end{tabular}

Fig. 4. Students per school day.

Question 4. Survey student socio-economic strata, is shown in Fig. 5:

\begin{tabular}{|c|c|c|c|c|c|c|}
\hline \multicolumn{7}{|c|}{ Question N. 4 } \\
\hline 1. Strata 1 & 2. Strata 2 & 3. Strata 3 & 4. Strata 4 & 5. Strata 5 & 6. Strata 6 & TOTAL \\
\hline 20 & 93 & 78 & 6 & 1 & 2 & 200 \\
\hline $10.00 \%$ & $46.50 \%$ & $39.00 \%$ & $3.00 \%$ & $0.50 \%$ & $1.00 \%$ & $100.00 \%$ \\
\hline
\end{tabular}

Fig. 5. Students and socio-economic procedence in Bogotá Colombia.

Question 5. Survey student age range of students. is shown in Fig. 6:

\begin{tabular}{|c|c|c|c|c|c|}
\hline \multicolumn{7}{|c|}{ Question N. 5 } \\
\hline $\mathbf{1 . 1 5 - 2 0}$ & $\mathbf{2 . 2 1 - 2 5}$ & $\mathbf{3 . 2 6 - 3 0}$ & $\mathbf{4 . 3 1 - 3 5}$ & $\mathbf{5 . ~ M o r e ~ 3 5}$ & TOTAL \\
\hline 61 & 123 & 12 & 3 & 1 & 200 \\
\hline $30.50 \%$ & $61.50 \%$ & $6.00 \%$ & $1.50 \%$ & $0.50 \%$ & $100.00 \%$ \\
\hline
\end{tabular}

Question 6. Survey student about male or woman sex, is shown in Fig. 7:

\begin{tabular}{|c|c|c|}
\hline \multicolumn{3}{|c|}{ Question N. 6} \\
\hline 1. Male & 2. Woman & TOTAL \\
\hline 69 & 131 & 200 \\
\hline $34.50 \%$ & $65.50 \%$ & $100 \%$ \\
\hline
\end{tabular}

Fig. 7. Type of sex to which the student belongs.

Question 7. You would like to download, install and interact with an application that will facilitate the consultation of tutorials, is shown in Fig. 8:

\begin{tabular}{|c|c|c|c|c|c|}
\hline \multicolumn{6}{|c|}{ Question $\mathbf{N} .7$} \\
\hline $\begin{array}{c}\text { 1.Totally } \\
\text { agree }\end{array}$ & $\begin{array}{c}\text { 2.Strongly } \\
\text { agree }\end{array}$ & 3. According & 4. Disagreement & $\begin{array}{c}\text { 5. Strongly } \\
\text { Disagree }\end{array}$ & TOTAL \\
\hline 89 & 40 & 60 & 7 & 4 & 200 \\
\hline $44.50 \%$ & $20.00 \%$ & $30.00 \%$ & $3.50 \%$ & $2.00 \%$ & $100.00 \%$ \\
\hline
\end{tabular}

Fig. 8. Results incidence of tutoring in academic education.

Question 8. Do you believe the tutorials can answer questions or concerns about topics covered in class that are not entirely clear in their academic training, is shown in Fig. 9.

\begin{tabular}{|c|c|c|c|c|c|}
\hline \multicolumn{5}{|c|}{ Question N. 8} \\
\hline $\begin{array}{c}\text { 1.Totally } \\
\text { agree }\end{array}$ & $\begin{array}{c}\text { 2.Strongly } \\
\text { agree }\end{array}$ & 3. According & 4. Disagreement & $\begin{array}{c}\text { 5. Strongly } \\
\text { Disagree }\end{array}$ & TOTAL \\
\hline 43 & 28 & 75 & 40 & 14 & 200 \\
\hline $21.50 \%$ & $14.00 \%$ & $37.50 \%$ & $20.00 \%$ & $7.00 \%$ & $100.00 \%$ \\
\hline
\end{tabular}

Fig. 9. Results of use of space for academic tutoring application.

Question 9. Suitably used spaces tutorials offered by the institution, is shown in Fig. 10:

\begin{tabular}{|c|c|c|c|c|c|}
\hline \multicolumn{5}{|c|}{ Question N. 9 } \\
\hline $\begin{array}{c}\text { 1.Totally } \\
\text { agree }\end{array}$ & $\begin{array}{c}\text { 2.Strongly } \\
\text { agree }\end{array}$ & 3. According & 4. Disagreement & $\begin{array}{c}\text { 5. Strongly } \\
\text { Disagree }\end{array}$ & TOTAL \\
\hline 59 & 24 & 48 & 58 & 11 & 200 \\
\hline $29.50 \%$ & $12.00 \%$ & $24.00 \%$ & $29.00 \%$ & $5.50 \%$ & $100.00 \%$ \\
\hline
\end{tabular}

Fig. 10. Results of use of space for academic tutoring application.

Question 10. The university has adequate space for the realization of academic tutoring, is shown in Fig. 11:

\begin{tabular}{|c|c|c|c|c|c|}
\hline \multicolumn{5}{|c|}{ Question N. 10 } \\
\hline $\begin{array}{c}\text { 1.Totally } \\
\text { agree }\end{array}$ & $\begin{array}{c}\text { 2.Strongly } \\
\text { agree }\end{array}$ & 3. According & 4. Disagreement & $\begin{array}{c}\text { 5. Strongly } \\
\text { Disagree }\end{array}$ & TOTAL \\
\hline 82 & 10 & 26 & 36 & 46 & 200 \\
\hline $41.00 \%$ & $5.00 \%$ & $13.00 \%$ & $18.00 \%$ & $23.00 \%$ & $100.00 \%$ \\
\hline
\end{tabular}

Fig. 11. Space infrastructure for attending academic tutoring.

\section{RESUlTS AND ANALYSIS}

Based on the information collected through the data collection tools designed for this purpose and the variables that were designed to be measured in such tools of the information obtained was classified as follows:

- Tool: Survey

- Sample: 200 students based CUN University

- Academic variables 
- Sociological factors

Academic programs: The University has programs with high demand from Bogota student population careers in management sciences, as in the case of business administration, tourism and hospitality management and international business on the other hand account with a great demand in the public accounting program and part of engineering, the Systems Engineering program finally worth mentioning the case of the graphic design program that features a $7 \%$ acceptance of the student community CUN, home center. Furthermore, we have programs where the number of students is very low, compared to the programs described above, such as public administration, design and production of fashion and social and journalism communication, this factor is that some universities have programs that they take a lot of time in the market offering such programs; these data are presented in Fig. 12.

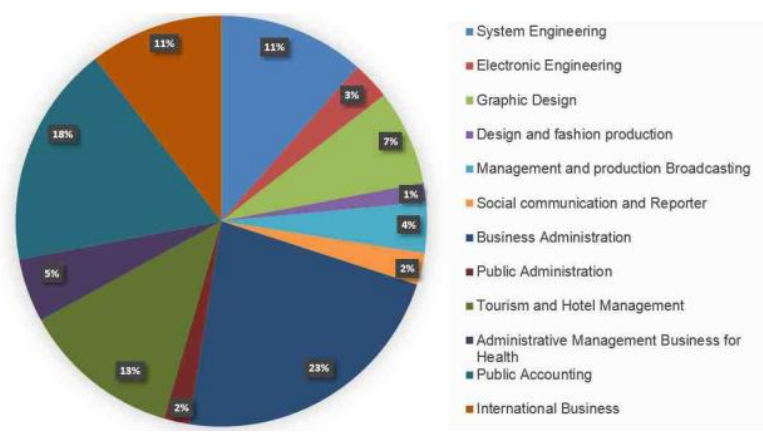

Fig. 12. Career distribution according to the number of college students.

Preparatory cycle: Most "Cunistas" students are conducting technical cycle in the different programs offered by the CUN at the headquarters center with a percentage covering more than half of the active students, it is important to note that the percentage shown by the students who are making the technology cycle has a difference of almost $40 \%$ over the technical cycle; this information is shown in Fig. 13, this could indicate that we are presenting a fairly high percentage of students dropping out or are opting to continue their studies in other institutions, on the other hand we can be satisfied with the percentage of students who are completing their professional course in college with $24 \%$ of the workforce.

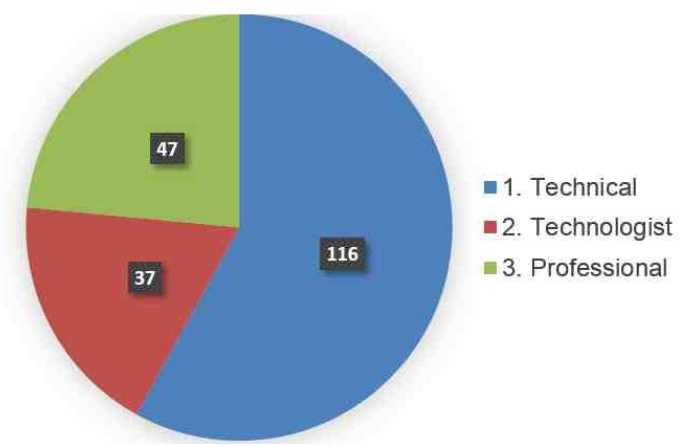

Fig. 13. Relationship and number of students according to their propedeutic cycle.

The Fig. 14 shows the day of class, the first in the morning and the second in the evening; is important to note most students take classes at night.

Near of $65 \%$ of students studying in the night shift because many of them are now working and for that reason can only pursue their studies in the day in question, as to students day shift represents $35 \%$ of the sample obtained, but bear in mind that the environment is different since most are now working or not economically dependent on their parents or their jobs in hours of the day.

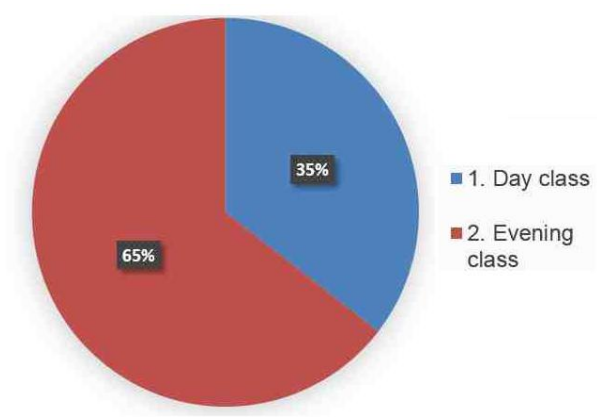

Fig. 14. Percentage and number of students in the morning and at night

The Fig. 15 shows the percent of student from low economic resources $46 \%$ represents near at strata 2 and $39 \%$ from strata 3 in Bogotá Colombia, total summary is near at $85 \%$ of total students.

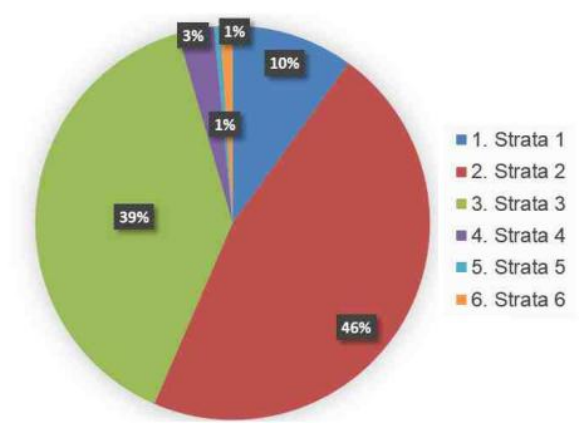

Fig. 15. Distribution student by economic resources.

\section{A. Biological Factors}

Age Ranges: The Fig. 16 shows most "Cunistas" students are very young age ranges between 15 and 25 years with an overall percentage of $91 \%$ of our student population range between 26 and 30 years and older ages we can see that the percent drop is significantly because they are mostly people who have worked much of his life and by factors such as time, various occupations and other factors have not had the space to further higher education studies.

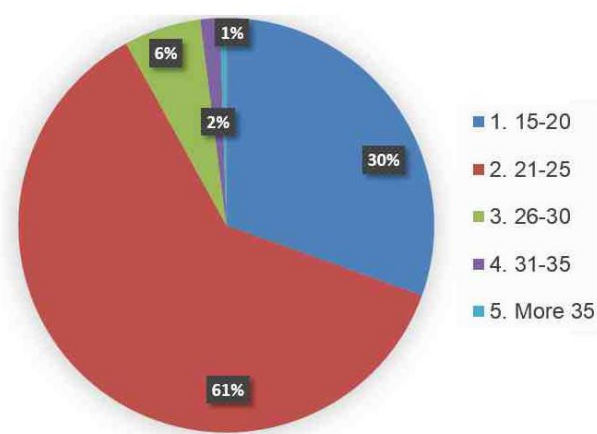

Fig. 16. Relationship of students according to age.

Male or Female: A large majority of students is female, with $66 \%$ of the results obtained (see Fig. 17), this is due to the incresed demand for women in management science programs such as business administration, international 
business and public accounting where most of the students are female. Moreover it can be established in programs such as Systems Engineering and Electronic Engineering in this programs their have more male students.

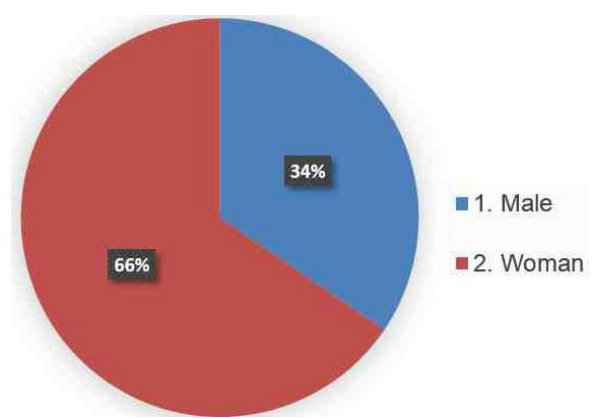

Fig. 17. Relationship of students according to their man or woman gender.

According to the aspects discussed above; they were asked students if they had to create a web application that allows access to a tutoring imparted by their teachers to which they replied that it was important that it would take place (see Fig. 18 ), $94 \%$ of students agreed with the development of an application of virtual tutoring

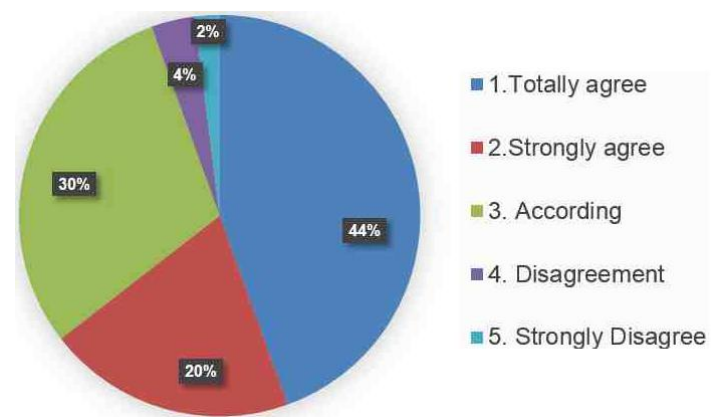

Fig. 18. Students agreed with the development of an application of virtual tutoring.

\section{B. Technical Aspects}

- Identification term mobile device phone: Most students interacted with mobile devices such as smart phones or tablets. On the other hand most of the students Cunistas based center are individuals aged 15 to 25 years a factor of great importance, since most students his age are very keen to have a high degree of interaction with technology and especially those with mobility features in their devices connected to wireless networks.

- Possible interaction with the application of consulting tutorials: In this regard there was a very good acceptance for most students to download, install and interact with a program to allow consultation schedules tutorial application, this is because Most students have had the opportunity to interact with some kind of A Web application for a specific purpose and are aware of its advantages, upgradeability, ease of use and functionality.

\section{WEP APPLICATION DESIGN}

Within the software development [12], one of the most important and momentous phase is the design because it can capture as the system will do. For this select, the object oriented, as this allows us to identify the most important elements of the system and their relationships and thus have an overview of the system as such architecture.

The architectural design is doing in 2 phases:

1) Architectural design: It focuses on the representation of the structure of the software components, properties, relationships [13] and interactions here UML [14] is used.

2) Design data: It facilitates the representation of data components of architecture [15].

Within the research project, development and implementation of an application for consultation of tutoring students of different educational programs based CUN center via Web two distinct but integrated components that are of equal importance was contemplated within the design and functionality of the proposed system:

1) The administrative application module: This module will be responsible for entering information related to the administration and management of student tutoring and its main components are:

Both administrative record to administer users and regular application information.

Registration or geographic location of headquarters

- Registry offices

- Register academic programs

- Subjects or Register

- Teachers or Register

- Register tutoring times and locations

- Export the information generated to a specific application

- Up or load the application to the Web site of the CUN

- Download and install the application

Finally, as a roadmap for both the administrative module to the Web module, the following components are set:

- Case Use diagram or general use

- Detailed case diagram use

- Functional requirements

- Non-functional requirements

Such modeling at the design level will reveal the role or function of each of the actors involved in the processes and how they interact with each of the components of the system, on the other hand will reveal each of the modules and their respective functionality and interaction between each.

This research project also includes the lifting of the respective functional and nonfunctional requirements for the design of library application software [16] but it is not necessary to show in this article because of the large amount of information generated.

\section{DESIGN OF THE GUI}

The aim of the Web application is to simplify the use of GUI applications for users is performed. In these cases, a simple mouse click on any image on the screen, replacing the tedious task of writing source code for the application interpreter must perform some type of action or proceeding. Within the research project, development and implementation of an application for consultation of tutoring students of different educational programs in the central headquarters of the CUN, we use of two different graphical 
interfaces built contemplated but which are of equally important in the design and functionality of the proposed system, is shown in Fig. 19:

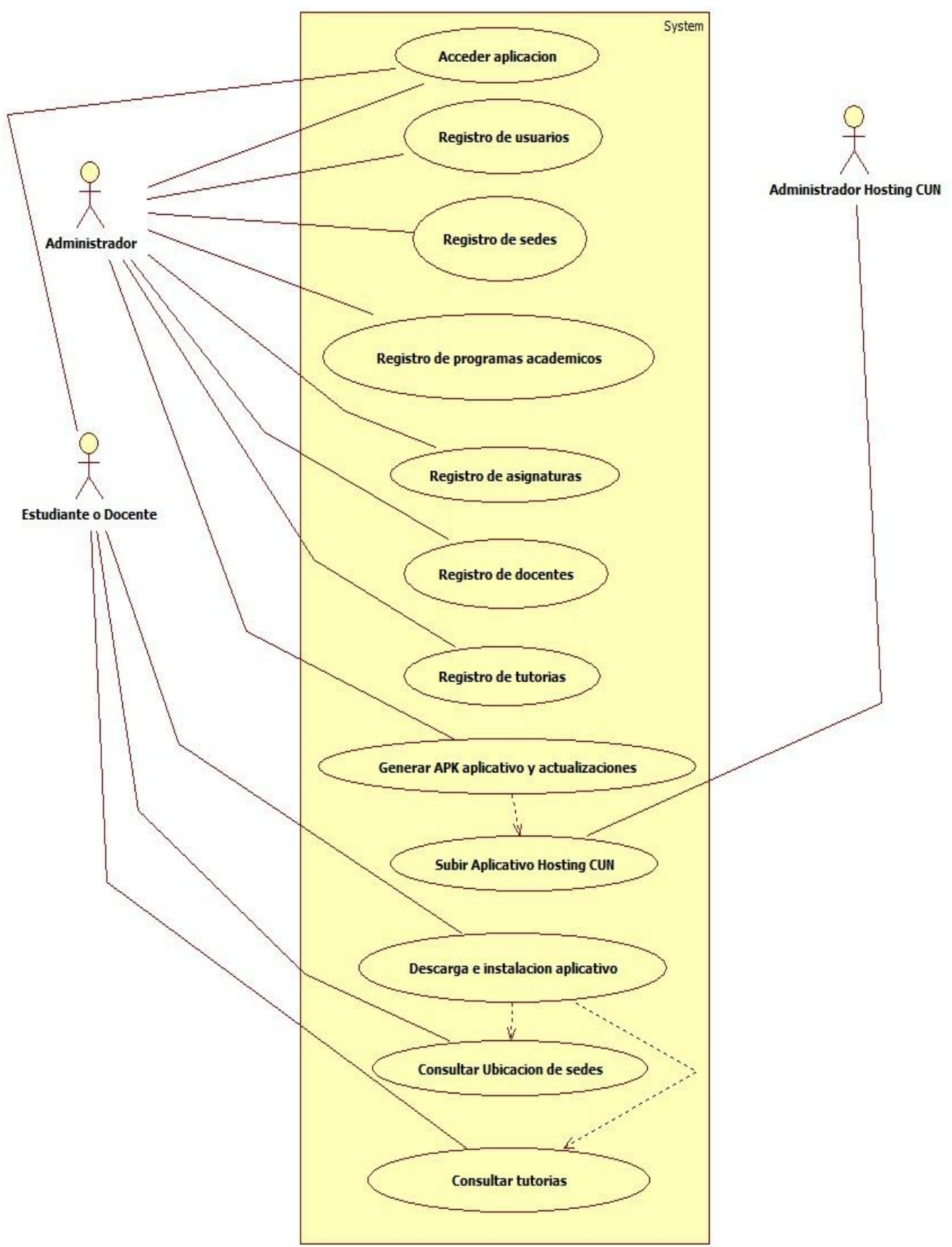

Fig. 19. UML use cases desingned to using for web application.

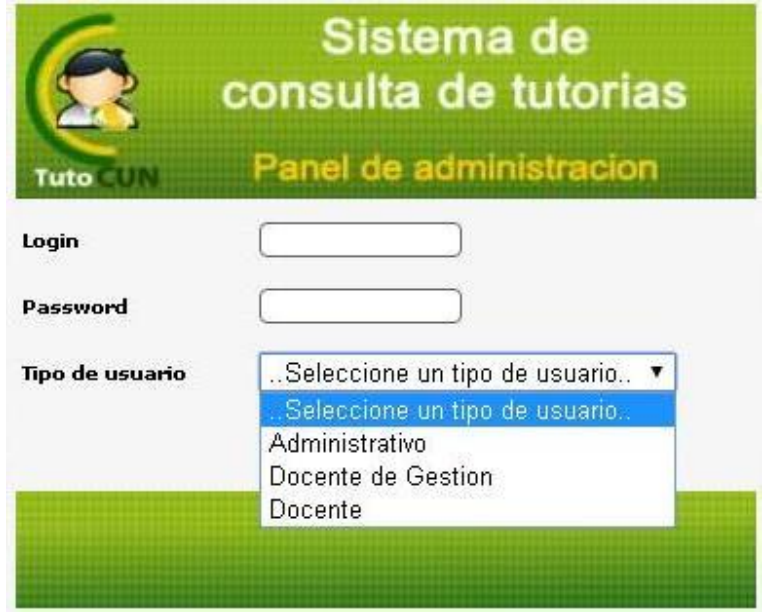

Fig. 20. User interface student and teacher Cunist.
Fig. 20 shows the developed software application, this contains three fields of information, first login request, the second password and the third the type of user that will access in this way you can use the application developed

\section{A. Administrative Module}

In this module, the system administrator would be responsible for entering information related to the administration and management of the tutoring of students, among its main components we have:

\section{B. Entry Form}

Through this form you check whether or not the user can access the application taking into account administrative permissions or user privileges as well: 
1) Administrative User: The super administrator of the application and has full permissions on all options of the application. Including insertion, modification, deletion, inquiry and reporting of information.

2) Regular User This type of user has only enabled the option to query and report on the information stored in the application.

\section{Administrative Panel}

Once the user enters their password this may enter the administrative panel where depending on the granted permissions can perform a set of specific processes, including user registration must, offices, academic programs, programs, courses, teaching and tutorials They are the main focus of this research, is shown in Fig. 21.

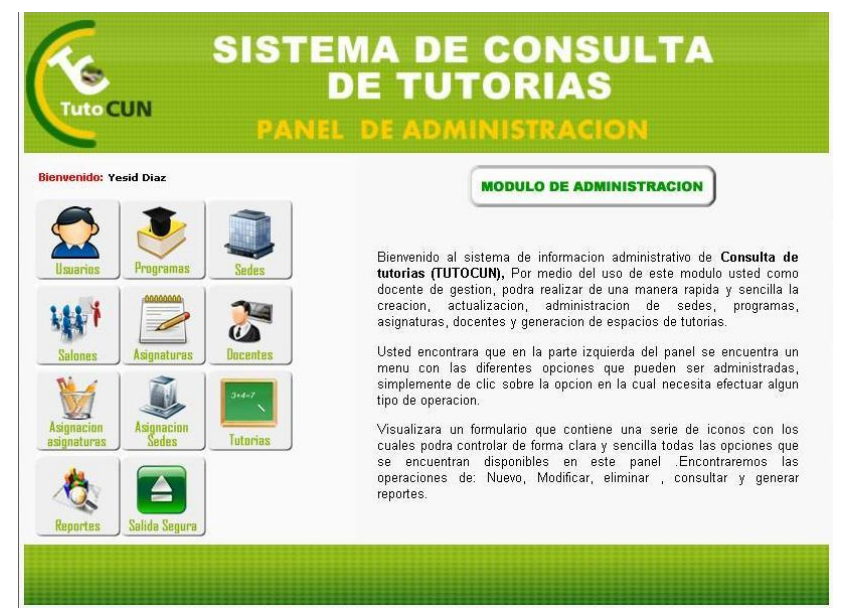

Fig. 21. Main view of the web application CUN for tutorial.

\section{CONCLUSION}

The use of academic spaces tutoring by students is not taken advantage of the best due to a combination of factors such as crossings schedules with classes, little information about the places and times of realization, inability to transfer from the site work, economic factor because as evidenced in the questionnaire in question number 4 we have $39 \%$ of students layer 2 and $46 \%$ of students layer 3 for a total of $85 \%$ of students Cunistas; other aspects have to do with little interest in participating in such academic areas.

The widespread use and acceptance of mobile devices worldwide and logically in Colombia has greatly contributed to the development of useful applications that have been well received by the Colombian community, an example, the application named Tapssi and application Web tutorials proposed in this paper found in initial tests before putting into production.

\section{ACKNOWLEDGMENT}

The authors wish to thank CUN people University, and the Axon Research group. This work was supported in part by a grant from the systems engineer students and research theachers.

\section{REFERENCES}

[1] S. N. Goulding et al., "Green droid: A mobile application processor for a future of dark silicon," IEEE Trans. Hot Chips, 2010.
[2] R. Bogdan and S. Biklen, Qualitative Research in Education: An Introduction to Theory and Methods, 3rd ed. Needham Heights, MA: Allyn \& Bacon. 1998.

[3] J. Cabero, "Bases pedagógicas del e-learning," Universidad y Sociedad del Conocimiento, in Madrid 2006, p. 110.

[4] A. Chua. (1997). Why KM projects fail: A multi-case analysis. Journal of Knowledge Management. [Online]. Available: http://www.emeraldinsight.com/doi/pdfplus/10.1108/1367327051060 2737

[5] UNESCO, "Case studies on integrating ICT into teacher education curriculum in Asia," in UNESCO, Bangkok, 2013 pp. 21-27

[6] K. Selhorst, "Putting 'knowledge management 2.0' into practice, The process of setting up a Wiki as a knowledge management tool in a public library," in Proc. the European Conference on Knowledge Management. Southampton, UK, 2008, pp. 807-816.

[7] D. D. Corkill, "Blackboard and multi-agent systems and the future," IEEE Trans. on Knowledge and Data Engineering, pp. 1-11, Massachusetts, 2004.

[8] V. Hien, "Learning to teach with ICT: A project-based course for pre-service teachers of biology at Hanoi National," in UNESCO, Hanoi, pp. 81-94, 2015.

[9] L. Wright, "Qualitative international management research," Handbook for International Management Research, Blackwell, Oxford, 1995.

[10] M. Haran, A. Karr, and M. Last, "Techniques for classifying executions of deployed software to support software engineering tasks," IEEE Trans. on Software Engineering, vol. 33, pp. 287-304, 2007.

[11] C. Dietrich and R. Tartler, "Understanding Linux feature distribution," in Proc. AOSD Workshop Modularity in Systems Software.

[12] J. Conallen. Modeling web application architectures with UML. [Online]. Available: http://dpinto.cs.buap.mx/semadoo/webapps.pdf

[13] D. Coleman and D. Skov, "Analysis and design for concurrent object systems," in Proc. Sixth International Conference on Software Engineering and Its Applications, Paris, 1993.

[14] G. Booch, J. Rumbaugh, and I. Jacobson. "Unified modeling language," Rational Software Corporation, Santa Clara, CA. 1996.

[15] M. Davis and R. Williams, "Software architecture characterization," in Proc. Symposium on Software Reusability, 1997, pp. 30-38.

[16] R. González. (2013). Dynamic, ecological, accessible and 3D virtual worlds-based libraries using OpenSim and Sloodle along with mobile location and NFC for checking in, [Online], Available: http://www.ijimai.org/journal/node/371

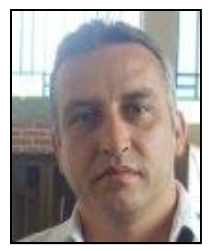

W. Ruiz was born in Armenia Colombia in 1966. He received the B.S. degree in systems engineer at 2005 from the Universidad Autonoma of Colombia. He is a researcher in development software and informatics topics in Axon group in CUN University.

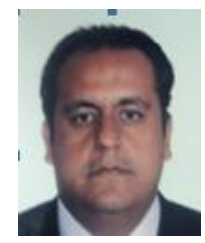

Y. Diaz was born in Bogotá Colombia in 1976. He received the B.S. degree of systems engineer, in 2000 at the Antonio Nariño University, master (c) at the Funiber on engineering systems, He is a researcher in informatics topics in Axon group in CUN University.

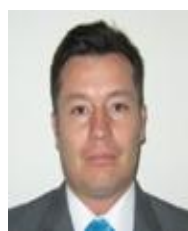

R. Ferro was born in Bogotá Colombia in 1972. He received the B.S. degree of electronic engineer, in 2000, at the Francisco José de Caldas University, the M.S degree the same University in computer networks in 2004; the Ph.D. degree at the Salamanca Spain University in informatic engineering in $2013, \mathrm{He}$ is a researcher on informatic topics and ITC, and the director of the Research Group LIDER and he participate how researcher in the Axon group in CUN University. 